
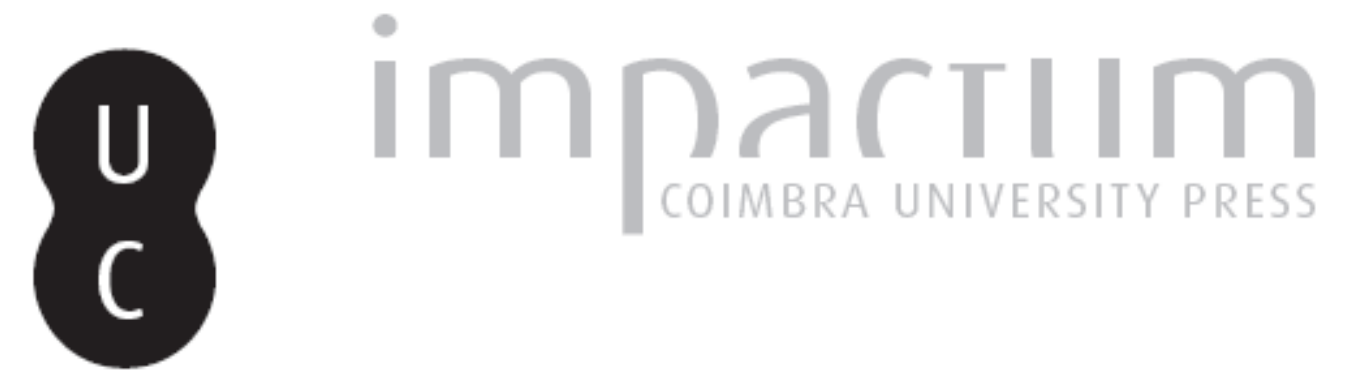

\title{
Aballay, el hombre sin miedo: um Western Borgeano
}

Autor(es): $\quad$ Medeiros, Rosângela Fachel de

Publicado por: Centro de Literatura Portuguesa

URL persistente:

URI:http://hdl.handle.net/10316.2/30064

DOI:

DOI:http://dx.doi.org/10.14195/2182-8830_1-2_5

Accessed : $\quad$ 26-Apr-2023 15:24:58

A navegação consulta e descarregamento dos títulos inseridos nas Bibliotecas Digitais UC Digitalis, UC Pombalina e UC Impactum, pressupõem a aceitação plena e sem reservas dos Termos e Condições de Uso destas Bibliotecas Digitais, disponíveis em https://digitalis.uc.pt/pt-pt/termos.

Conforme exposto nos referidos Termos e Condições de Uso, o descarregamento de títulos de acesso restrito requer uma licença válida de autorização devendo o utilizador aceder ao(s) documento(s) a partir de um endereço de IP da instituição detentora da supramencionada licença.

Ao utilizador é apenas permitido o descarregamento para uso pessoal, pelo que o emprego do(s) título(s) descarregado(s) para outro fim, designadamente comercial, carece de autorização do respetivo autor ou editor da obra.

Na medida em que todas as obras da UC Digitalis se encontram protegidas pelo Código do Direito de Autor e Direitos Conexos e demais legislação aplicável, toda a cópia, parcial ou total, deste documento, nos casos em que é legalmente admitida, deverá conter ou fazer-se acompanhar por este aviso.

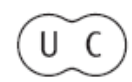




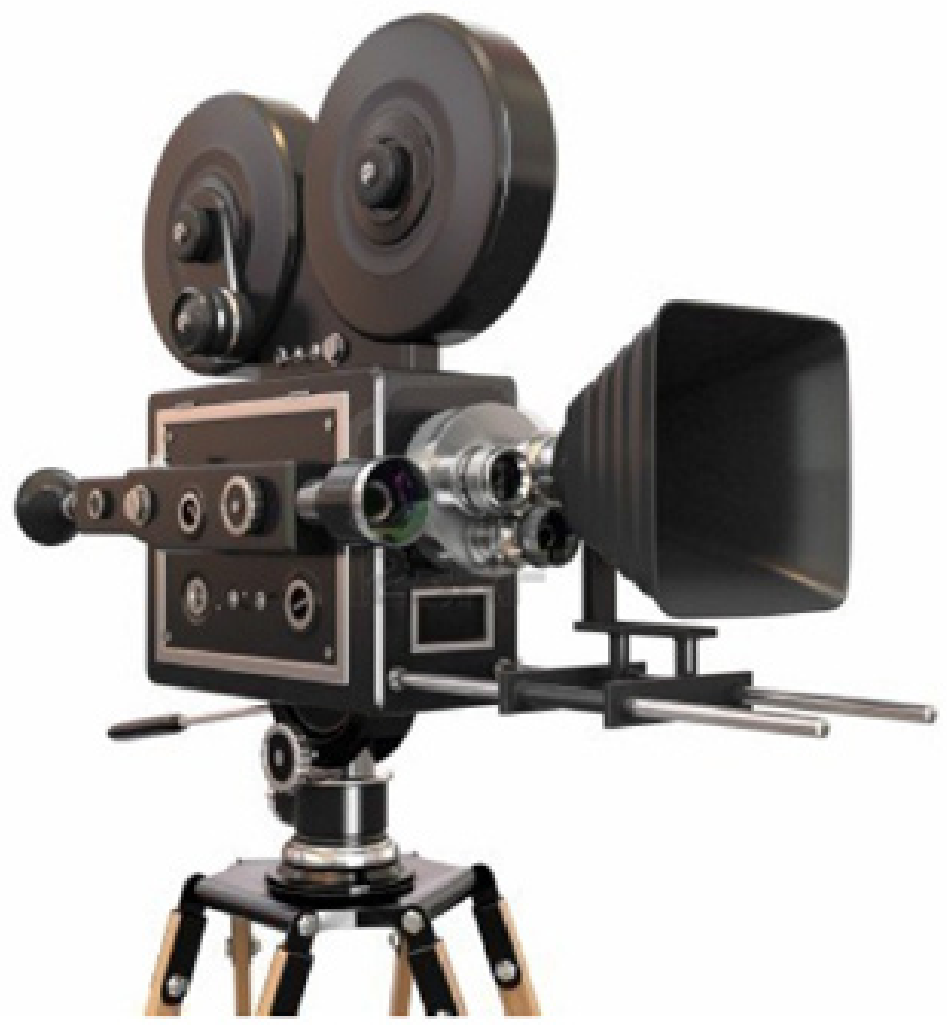

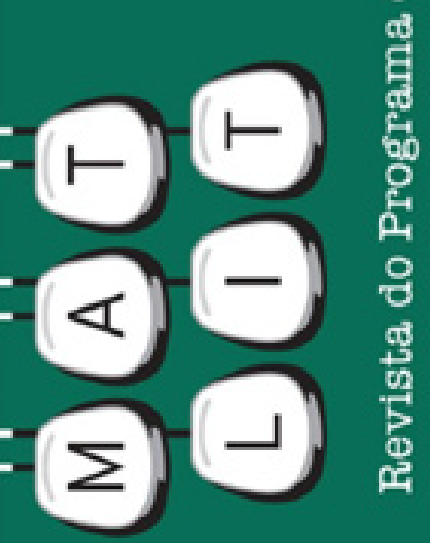

Vol. 1.2 (2013)

ISSN 2182-8830

'Escrita e Cinema'

Osvaldo Manuel Silvestre

\& Clara Rowland (orgs.) 


\title{
Aballay, el hombre sin miedo: Um Western Borgeano RosÂNGELA FACHEL DE MEDEIROS
}

\author{
Universidade Federal do Rio Grande do Sul
}

\begin{abstract}
Resumo
Aballay, el hombre sin miedo (2010), de Fernando Spiner, tradução cinematográfica do conto "Aballay", de Antonio Di Benedetto (escrito entre 1975 e 1976), parte do texto para rearticular elementos da Gauchesca argentina, presentes na literatura e no cinema, a elementos do Western, clássico e spaghetti, em um jogo de transculturação. Este artigo apresenta as duas versões de Aballay, conto e filme, para analisar as relações que essas obras estabelecem com as tradições que são revisitadas pelo cineasta no processo de realização do filme. E, sendo esta análise norteada pela percepção de que o fazer cinematográfico de Spiner é borgeano na forma e no conteúdo, a obra Jorge Luis Borges surge como intertexto teórico e narrativo. Palavras-chave: Cinema; Tradição Gauchesca; Western; Antonio Di Benedetto; Fernando Spiner; Jorge Luis Borges.
\end{abstract}

\section{Abstract}

Six Shooters (2010), by Fernando Spiner, a cinematic translation of the short story "Aballay" by Antonio Di Benedetto (written between 1975 and 1976), uses the text as a starting point for articulating elements of the Argentine gauchesque, in literature and in cinema, with elements of Western, classic and Spaghetti, in a game of transculturation. This paper presents the two versions of Aballay, short story and film, in order to analyze the relationships that are established between these works and the traditions revisited by the filmmaker in the process of making the film. Considering that my analysis is guided by an understanding that Spiner's filmmaking is Borgian in form and in content, the work of Jorge Luis Borges emerges as theoretical and narrative intertext. Keywords: Cinema; Gauchesque Tradition; Western; Antonio Di Benedetto; Fernando Spiner; Jorge Luis Borges.

\section{Da página à tela: Fernando Spiner, autor de Aballay}

ballay, el hombre sin miedo $(2010)^{1}$, de Fernando Spiner, é a
transcriação cinematográfica do conto "Aballay", de Antonio Di
Benedetto, cujo roteiro, escrito por Spiner, Javier Diment e Santiago Hadida, parte da narrativa gauchesca para criar um Western.

O conto de Di Benedetto apresenta a história de Aballay, um gaucho ${ }^{2}$, que, após assassinar um homem, não consegue esquecer o olhar do filho de

1 Aballay foi escolhido pela Academia Cinematográfica Argentina para representar o país na competição ao Oscar de Melhor Filme Estrangeiro de 2012. Além disso, o filme participou de diversos festivais internacionais, sendo agraciado com outras premiações.

2 Optou-se por manter a escrita castelhana, gaucho, ao invés de sua versão portuguêsa, gaúcho, para sinalizar que apesar das semelhanças notórias há diferenças entre as 
sua vítima. Assombrado pela culpa, Aballay escuta o sermão de um padre sobre os Estilitas, que buscavam a expiação vivendo sobre as colunas de antigos templos destruídos, e decide copiar destes a penitência. Sem as colunas, Aballay monta em seu cavalo para nunca mais apear. O gaucho que nunca desce de seu cavalo ganha fama e, aos poucos, se transforma em um mito que é convertido em Santo. Passam-se os anos e o filho do assassinado, já adulto, volta em busca de vingança. Durante o embate entre eles, Aballay sem querer fere gravemente a seu oponente e decide baixar do cavalo para socorrê-lo. Preocupado por estar quebrando sua promessa, Aballay se distrai e recebe uma punhalada fatal.

Ao ler o texto de Di Benedetto, Spiner reconheceu na narrativa gauchesca os elementos basilares do gênero Western: os homens a cavalo, o território sem leis, o império das armas, o desejo de vingança e o duelo; corroborando sua ideia de que o Western é um gênero genuíno na história argentina, atravessada pela violência, pela conquista, pela vingança e por homens a cavalo. Assim, a partir do texto intimista, que se centra na expiação de Aballay, Spiner criou um Western gaucho, um filme de ação repleto de tensão e no limite da violência com lutas, degolas, tiros e duelos.

O conflito interno vivido por Aballay, que norteia o conto, é expandido pelo filme que traz o conflito para o exterior apresentando-o na dicotomia entre as personagens de Aballay (o assassino) e Julian (o vingador). Para tanto, Spiner amplia o enredo de Di Benedetto, inserindo-lhe novos episódios como o da história de Julián, que ao tornar-se adulto volta para vingar o pai. Personagem secundário, mas decisivo na narrativa literária, o jovem vingador é transformado em coprotagonista da narrativa fílmica e ganha um nome: Julián; ele corporifica a honra do gaucho. No extremo oposto, aparece El Muerto, personagem que não existe no conto, que assume a liderança da corja de gauchos após atraiçoar Aballay e que representa o gaucho mau.

Com o intuito de realizar um Western gaucho, ou seja, transpor para um imaginário regional uma estética canônica hollywoodiana, Spiner realizou no cinema o que Ángel Rama denominou, em relação à Literatura LatinoAmericana, como transculturação: apropriação de elementos estrangeiros para revitalização de elementos próprios, que, ao invés de cederem à influência cultural, dela se nutrem, mas também a afetam. ${ }^{3}$ Dessa forma, Aballay dialoga com o Western, hollywoodiano e spaghetti, transculturando a estrutura narrativa e elementos do gênero como: a crueldade, a selvajaria, a opressão e o machismo, para a gauchesca argentina.

tradições gauchescas existentes na Argentina e no Brasil.

3 Em meu texto "A transculturação como estética dos Cinemas Latino-americanos", publicado na Revista Imagofagia, analiso a recorrência da transculturação nas produções cinematográficas contemporâneas da região. Disponível em:

http://www.asaeca.org/imagofagia/sitio/index.php?option=com_content\&view=arti cle\&id=240:a-transculturacao-como-estetica-dos-cinemas-latino-

americanos\&catid $=48 \&$ Itemid $=132$ 
A leitura/tradução que Spiner realiza do texto de Di Benedetto dialoga com a poética da tradução borgeana definida como processo de leitura (interpretação e reescritura), como produção. A tradução como uma leitura ativa do texto, que se iguala ao processo de escritura, envolvendo como esta: "apropriações, transposições, deformações" (Carvalhal, 2003: 221). E neste processo de recriação cinematográfica do conto, Spiner entretece transculturalmente múltiplas vozes, entre as quais se destacam: a gauchesca, o Western, o Western Spaghetti e a obra de Borges.

\section{O Western gaucho}

O filme de Spiner insere-se na tradição do Gênero Western consagrado por diretores como John Ford, Sam Peckinpah e Anthony Mann, pois conforme afirma o diretor:

Hay coincidencias geográficas y sociales entre la vida rural del lejano oeste norteamericano y la pampa sudamericana: grandes extensiones no conquistadas, hombres que viven a caballo y una ley ausente, que deja lugar al culto de las armas y la pelea, el relato agrega lo componentes de la venganza y el duelo, que es una problemática propia del género humano, y aborda, así, una temática de alcance global (Spiner apud Di Benedetto, 2010: 43).

No entanto, essa não é uma novidade no cinema argentino, outros cineastas realizaram essa fusão do gênero à realidade campeira da Argentina, dando origem a uma tradição conhecida como Western gauchesco: Nobleza gaucha (1915), Viento Norte, de Mario Soffici (1937); La guerra gaucha (1942), de Lucas Demare; Pampa bárbara (1945), de Demare e Hugo Fregonese; e Juan Moreira (1973), de Leonardo Favio.

A versão cinematográfica de Aballay é construída a partir da estrutura fundamental do Western: o resgate da ordem realizado pelo herói (cowboy/ gaucho), que conforme Gomes de Mattos, acontece em resposta a três situações: "A reabilitação do nome do herói, o resgate da mocinha em perigo ou a vingança de um pai ou irmão assassinado". (Mattos, 2003: 24), todas presentes no filme. Para Spiner, seu filme "es un Western porque toma los tópicos fundamentales del género: la venganza, un territorio sin ley, la violencia, la ley del más fuerte, hombres de a caballo" (Ranzani, 2010).

Contudo, Aballay pode ser reconhecido como uma reconfiguração do gênero, ao estilo dos que André Bazin denominou "meta-Western", pois transcende o próprio gênero, subvertendo-o no campo estético, sociológico, moral, psicológico e político (Bazin, 1991). A linguagem cinematográfica dos Westerns é transposta para o cenário criollo, as clássicas tomadas panorâmicas do gênero destacam a beleza do encontro entre o azul do céu e o 
avermelhado da terra, atravessado pelos gauchos que parecem fusionados aos seus cavalos no balé do galope. Neste contexto, muitos dos elementos agregados durante o processo de transposição do texto literário para a tela: o bando de foras da lei, o assalto à carruagem e a história da busca por vingança de Julián e de seu envolvimento amoroso com Juliana, revelam a recriação do gênero. Além disso, a figura de Aballay incorpora um dos códigos identificados por Eduardo Geada como responsáveis pela “desconstrução ideológica do lugar-comum cinematográfico" (Geada, 1978: 22) no spaghetti Western: o herói, acompanhado de um cavalo e uma pistola (uma adaga) como extensões do próprio corpo, habitando o cenário clássico do Western - o deserto.

Mas, apesar das semelhanças entre o contexto do Western e da gauchesca, Borges faz questão de apontar diferenças entre o gaucho e "su remoto hermano del Far West", o cowboy. Pois, ao contrário deste que era "un aventurero, un buscador de largas tierras vírgenes o de filones de oro", foram as guerras que levaram o gaucho a tão longe (Borges, s/d: 42). Aballay, com seu passado de penas desconhecido, confirma a percepção de Borges, sendo muito mais gaucho que cowboy.

\section{A Gauchesca na literatura argentina}

A filiação de Aballay, conto e filme, à Tradição Gauchesca argentina, que nasce na literatura e se prolonga no cinema nacional, é evidente. E a relação do filme de Spiner com a literatura nacional não se restringe ao fato de ser a transcriação de uma obra literária, mas se expande para a própria narrativa fílmica, que em sua linguagem específica reelabora mitologias de um passado rural recorrente na Literatura Gauchesca argentina; que, por sua vez, está arraigada ao folhetim periodístico, ao teatro e à canção nativa.

Conforme Josefina Ludmer (1988), o gênero gauchesco surgiu e se desenvolveu como resposta à necessidade de uso da voz do gaucho por parte dos escritores letrados em contrapartida ao uso de seu corpo nas guerras civis e como mão de obra nos grandes latifúndios. A imagem do gaucho errante, às margens da civilização, evoca uma aparente condição de ilegalidade, que corresponde à contraposição existente entre a lei jurídica, escrita (decorrente de uma lei central) e o código da tradição e do habito, oral (que rege as relações da comunidade campeira).

A gauchesca centra-se na figura do "gaucho", denominação de origem incerta, que não define uma etnia, mas sim um modo de vida, uma identidade híbrida de mestiços e criollos que ao não serem aceitos nem por brancos nem por índios decidem levar uma vida praticamente nômade, condição da qual deriva o típico caráter gaucho: altivo, reservado, melancólico e um tanto desconfiado. Segundo Borges, é inútil definir eticamente o "gaucho: hijo 
casual de olvidados conquistadores y pobladores, fue mestizo de indio, a veces de negro, o fue de blanco. Ser gaucho fue su destino" (Borges, s/d: 42).

Maltratado e perseguido, o gaucho, personagem desta literatura, utiliza sua linguagem peculiar para evocar um código de valores que está alicerçado à sua masculinidade, à sua coragem individual e à sua tenência frente aos golpes do destino, os quais se personificam geralmente na figura de um oponente. Nesse contexto, são recorrentes as histórias que abordam os conflitos criados em laços de amizade e de ódio, que geralmente culminam em duelos mortais.

A construção da figura do gaucho inicia em Facundo - Civilización y Barbarie (1845), de Domingo Faustino Sarmiento. Com o pressuposto de estudar a vida de Facundo, Sarmiento constrói uma explicação acerca da realidade argentina visando compreender o governo autoritário de Juan Manoel de Rosas (1835-1852). Através da figura de Facundo, um caudilho que se entrepôs ao projeto de modernização do país, Sarmiento personifica a barbárie advinda do campo e constrói a imagem do gaucho: "Facundo não é cruel, não é sanguinário; é o bárbaro, somente, que não sabe conter suas paixões e que, uma vez irritadas, não conhecem freio nem medida" (Sarmiento, 1996: 236). O gaucho de Sarmiento é produto da fatalidade do meio: o campo é um lugar de vida selvagem e da barbárie indígena, que influencia seus habitantes, levando-os ao estado de natureza; não há sociedade. Em contraponto, Buenos Aires é o ambiente da sociedade européia. E o fato de ser o gaucho um mestiço, do encontro entre espanhóis e índio; sendo, para Sarmiento: os primeiros atrasados e medievais e os segundos, caracterizados pela barbárie pura; marcaria sua identidade: preguiçoso, brutal, supersticioso, hábil no uso da faca, vaqueiro experiente e cantor. O gaucho de Sarmiento é o contrário do homem civilizado, avesso às leis e também à cultura letrada, seu conhecimento empírico e rudimentar é suficiente para o ambiente em que vive. Para Sarmiento, existem quatro tipos de gauchos: o matreiro, o mau, o cantor e o vaqueano. E a essência do "gaucho mau" está na natureza bárbara do mestiço, traço selvagem que se agrava mais ainda no índio e no negro.

Já os feitos de Santos Vega, um gaucho trovador invencível que, conforme a lenda, só foi derrotado pelo Diabo, foram contados por Bartolomé Mitre em 1838, por Hilario Ascasubi em 1872 e por Rafael Obligado em 1877.

E o popular poema épico El Gaucho Martín Fierro (1872), de José Hernández, narra em primeira pessoa as agruras vividas pelo protagonista, que convocado pelo exército para servir defendendo a fronteira Argentina, deserta para regressar a sua família, mas não a encontra. Durante suas andanças, o gaucho ofende a uma mulher negra em um bar, provocando o companheiro desta a um duelo de honra fatal. Fierro torna-se um bandido perseguido pela milícia, mas em sua fuga adquire um amigo, o Sargento Cruz, que a ele se une por admirar sua bravura. Na busca de uma vida melhor, Fierro e Cruz decidem ir viver entre os índios. 
O poema de Hernández é uma denúncia de que a tentativa de integrar o gaucho à civilização através da obrigação de servir ao exército, que o maltratou e humilhou, acabou por anulá-lo enquanto força produtiva, impelindo-o à deserção e transformando-o em delinqüente (matreiro, assassino, ladrão, fugitivo) que só teve como refúgio estar entre os índios, apresentando assim uma imagem idealizada do gaucho e consagrando o linguajar gauchesco. Mas em La vuelta de Martín Fierro (1879), apesar de manter a denúncia da injustiça social, Hernández aconselha o gaucho a se conciliar com a civilização que antes era depreciada.

A imagem do gaucho astuto e audaz é propagada por Juan Moreira (1879), de Eduardo Gutiérrez. Vítima da injustiça, da humilhação e do autoritarismo, Moreira se rebela contra as leis da sociedade e isso justifica sua violência: "El gaucho habitante de nuestra pampa tiene dos caminos forzosos para elegir: uno es el camino del crimen, [...]; otro es el camino de los cuerpos de línea, que le ofrecen su puesto de carne de cañón" (Gutiérrez, 2012: 6). O gaucho matreiro se converte em herói ao rebelar-se contra o destino que é reservado a sua classe pelas elites, assumindo como sua única lei a palavra de honra. Moreira se deixa matar para preservar os valores de sua casta: bravura, honra, solidariedade e integridade do gaucho.

Em El payador (1916), Leopoldo Lugones institui o gaucho e a cultura criolla como origem da identidade nacional frente à "invasão" dos imigrantes.

El gaucho influyó de una manera decisiva en la formación de la nacionalidad por ser elemento conciliador y a la vez diferencial entre el indio y el español. Todo cuanto es origen nacional viene de él: la guerra de la independencia, la guerra civil, la guerra con los indios. No lamentemos, sin embargo, con exceso su desaparición que fue un bien para el país, porque el gaucho contenía un elemento inferior en su parte de sangre indígena (Lugones, 1991: 38).

Assim como Sarmiento, Lugones vai buscar a origem do gaucho no encontro entre espanhóis e índios, mas dando ênfase às características do indígena, que não mais é visto como atrasado e selvagem, e à herança helenística trazida pelos espanhóis. O gaucho é transformado em herói civilizador, que contribui para o desenvolvimento da civilização argentina: heróico, viril e superior aos recém-chegados por sua valentia e por seus conhecimentos autóctones. Lugones proclama o gaucho como legítimo representante do país, símbolo da argentinidade, e Martín Fierro como poema épico nacional. No entanto, as qualidades civilizatórias reconhecidas por Lugones no gaucho serão para ele decisivas em sua transformação em sujeito agrário, peão rural submisso e obediente.

Don Segundo Sombra (1926), de Ricardo Güiraldes, é narrado em primeira pessoa por Fábio, que, maltratado pelas tias, encontra em Don Segundo Sombra um modelo a seguir com quem empreende uma jornada para 
aprender a ser um bom gaucho e converter-se em homem. O livro representa o fim da época gauchesca, para Jacques Joset (1987), foi a consciência do desaparecimento do gaucho na vida real que levou o autor a ressuscitá-lo, transformando-o em um personagem mítico, que surge como ideal de uma identidade genuinamente argentina. Esse gaucho idealizado, virtuoso e heróico, que vive em perfeita harmonia com a natureza, guiado por ideais de liberdade e de individualismo, alimentou a criação do estereotipo do gaucho cultuado na Argentina, no Uruguai e no sul do Brasil. O texto de Güiraldes busca resgatar as raízes nacionais na figura do gaucho platino e na natureza.

Aballay, de Di Benedetto, retoma a tradição gauchesca e a figura do gaucho como protagonista, remetendo assim aos emblemáticos: Martín Fierro e Juan Moreira. Mas, enquanto as obras anteriores possuíam conotações políticas, o conto de Di Benedetto centra-se no sentimento de culpa que corrói seu herói, não dando importância às condições sociais em que ele vive. E tampouco apresenta o passado do gaucho como justificativa para seus atos, como o fizeram seus antecessores. Aballay se diferencia de Fierro e de Moreira, igualmente assassinos, por sentir culpa pelo crime que cometeu. Mas enquanto estes, perseguidos pela lei, se tornam desterrados a vagar em fuga; Aballay escolhe o mesmo destino como forma de expiação.

O conto amalgama o texto bíblico à tradição literária gauchesca argentina, criando uma narrativa híbrida à margem do cânone literário, como o próprio Di Benedetto. A religiosidade apresentada pela narrativa é sincrética, construída por um povo que está no limiar entre civilização e barbárie, entre o europeu e o autóctone; na qual os ensinamentos cristãos se misturam às crenças e aos conhecimentos indígenas. Aballay representa um momento em que a modernização, forjada com o sacrifício do povo, resulta na consolidação de dois mitos: "simbolizados en el rebelde y el santo, estimulando a adesão de los estratos inferiores que sacralizaron ambas figuras en tanto portadores de la resistencia a la opresión de los poderes; figuras románticas que desafiaban el orden injusto de la sociedad” (Rama, 1984: 7576). A partir deste viés místico e religioso, que apresenta uma reflexão acerca da violência a partir da culpa de quem a inflige, Di Benedetto ressignifica a gauchesca e problematiza a figura do gaucho.

\section{A Gauchesca no cinema argentino}

O cinema gauchesco argentino deriva diretamente da tradição literária. Considerado filme fundador do gênero, Nobleza gaucha - 1915 (filme mudo em branco e preto e maior êxito de bilheteria nacional do cinema no período), de Humberto Cairo, Enrique Ernesto Gunche e Eduardo Martínez de la Pêra, parte dos poemas Martín Fierro e Santos Veja. Assim também os filmes de Mario Saffici, Viento norte - 1937, e Prisioneros de la tierra - 1939, foram inspirados respectivamente em um capítulo de Una excursión a los indios 
ranqueles (1870) e em contos de Horacio Quiroga. E Huella - 1940, de Luis José Maglia Barth, nasceu de fragmentos de Facundo.

La guerra gaucha (1942), de Lucas Demare, adaptação do romance homônimo de Leopoldo Lugones, já se apresenta como um relato épico com cenas de ação e de externas que remetem ao Western. Mas é em Pampa bárbara (1945), de Lucas Demare e Hugo Fregonese, roteiro original de Ulises Petit de Murat e Homero Manzi, que o Western se apresenta em toda sua ação, violência e crueza. A aproximação se revela ainda na presença de elementos recorrentes do gênero: as grandes paisagens, a vida nos fortes, a ausência da lei, a ameaça dos bárbaros, os militares e o gaucho/cowboy. Além disso, o filme traduz com verdade para o contexto argentino a relação entre o homem e a paisagem, fundamental ao Western.

Já a adaptação de Martín Fierro (1968), de Torre Nilsson, bem como a adaptação de Don Segundo Sombra (1968), de Manuel Antín, criam uma gauchesca que não se aproxima tanto ao modelo do Western.

Juan Moreira foi levado cinco vezes para as telas do cinema. Duas vezes durante a época do cinema mudo, em 1908 e 1923, e as seguintes já no cinema sonoro dirigido por Nelo Cosimi, em 1936; por Luis José Moglia Barth, em 1948, e sua versão mais consagrada com a direção de Leonardo Favio, em 1973.

Aballay, de Spiner, não apenas se insere à tradição gauchesca do cinema argentino, mas a recria e transforma ao abordá-lo por um novo viés que não o pampa, mas os Valles Calchaquíes com sua importante influência indígena, com sua gente, "su cultura, su forma de hablar, sus copleras, esa mezcla entre lo indígena y lo europeo" (Spiner apud Di Benedetto, 2010: 43). Redescobrindo a figura do gaucho como personagem "con la liturgia de sus armas, su relación con la ley y su intima vinculación con el caballo, protagonista fundamental de la colonización" (Spiner apud Di Benedetto, 2010: 43).

$\mathrm{Na}$ esteira das obras de Saffici, Petit de Murat, Manzi, Demare, Fregonese e Favio, Spiner sinaliza como precursores de seu filme: Nobleza gaucha, Pampa bárbara e Juan Moreira, dando destaque a Pampa bárbara, que para ele é o grande referencial do Western no cinema argentino e declarando sua admiração a Fregonese, único diretor argentino a ter uma carreira relevante em Hollywood, tendo realizado muitos Westerns.

\section{A gauchesca borgeana}

A literatura gauchesca foi um tema recorrente na literatura/reescritura de Jorge Luis Borges, que retomou a figura do gaucho no início do Século XX, rompendo com a tradição clássica de Sarmiento e de Lugones e lendo a gauchesca a partir de suas qualidades de desafio, de apego às tradições, de bravura e do "tempo mítico", as quais para ele são intrínsecas ao gênero. 
Durante toda a sua vida literária, Borges manteve uma relação estreita e complexa com El Martín Fierro, que para ele "es un libro muy bien escrito y muy mal leído. Hernández lo escribió para mostrar que el Ministerio de Guerra [...] hacía del gaucho un desertor y un traidor; Lugones exaltó ese desventurado a paladín y lo propuso como arquetipo. Ahora padecemos las consecuencias" (Borges, 1968: 93). Borges elogia o texto de Hernández, mas rechaça seu personagem. E faz questão de pontuar sempre a separação entre a moral "falha" de Martín Fierro e o valor da obra.

A partir dessa relação intensa com Martín Fierro, Borges escreve seus contos hernadianos: "Biografía de Tadeo Isidoro Cruz (1829-1874)", publicado em 1944, o qual traz como protagonista um personagem secundário do poema; e "El fin", publicado em 1953, que dá fim às aventuras de Fierro, que nesta narrativa morre no duelo com o negro que vem vingar o assassinato de seu irmão. Borges se apropria da obra de Hernández e sobre ela age de forma critica, transformando-a, recriando-a e expandindo-a.

A tradição gauchesca está presente ainda em seus contos: "El Sur" (1944) e "La otra muerte" (1949). "El sur" narra o retorno fantástico de Dahlmann ao Sul, onde nunca estivera, e à linhagem gaucha para morrer em um duelo de facas. Em "La otra muerte" há outra viagem fantástica, mas desta vez no tempo, através da qual Damián regressa para morrer na batalha de Masoller à qual sobrevivera por covardia. E em "La noche de los dones" (1975), Borges reconta o final de Juan Moreira através do relato de um ancião que quando jovem assistira ao assassinato de Moreira.

O gaucho borgeano não se submete ou se adapta à civilização, pois sua identidade implica o desafio e a bravura e a adaptação à civilização representaria sua destruição. Desta forma, ele escolhe morrer em sua lei, resistindo. "Ser gaucho fue un destino. Aprendió el arte del desierto y de sus rigores; sus enemigos fueron el malón que acechaba tras el horizonte azaroso, la sed, las fieras, la sequía, los campos incendiados [...]. Su pobreza tuvo un lujo: el coraje" (Borges, s/d: 42).

O gaucho dos contos de Borges habita um "tempo mítico", concepção de tempo que se tornou recorrente nas narrativas latino-americanas, definido por Octavio Paz como:

un tiempo en que el tiempo no era sucesión y tránsito, sino manar continuo de un presente fijo, en el que estaban contenidos todos los tiempos, el pasado y el futuro (...). El tiempo cronométrico es una sucesión homogénea y vacía de toda particularidad. (...) sólo transcurre. El tiempo mítico, al contrario, no es sucesión homogénea, de cantidades iguales; (...) es largo como la eternidad o breve como un soplo (Paz, 1990: 188- 190).

Esse tempo mítico, um tempo fora do tempo, no qual passado, presente e futuro coexistem e se expandem por veredas que se bifurcam, se cruzam e 
se amalgamam através da imaginação, do sonho e da alucinação, é o "tempo borgeano" por excelência.

\section{Aballay - um Western borgeano}

O diálogo intertextual com a obra de Borges já existe no texto de Di Benedetto, seu contemporâneo. Reconhecemos em Aballay, tanto no conto quanto no filme, a instauração de um "tempo borgeano". No conto, a narrativa no presente é invadida pelo tempo mental do protagonista que se projeta para o passado remoto dos estilitas e para suas memórias do crime, fazendo com que passado e presente se imbriquem. Como observa Julio Cortazar:

En "Aballay", esta presencia desde el pasado se da como un juego óptico alucinante: el personaje se sitúa en el tiempo mental y místico de los estilitas, y el autor en el tiempo del personaje, la pampa argentina del siglo diecinueve. Un pasado próximo se hunde así en otro pasado remoto; de ese juego de ecos temporales nace, creo, la intensa reverberación de "Aballay", su caracol ahondando en el oído del lector, una interminable teoría de retrocesos (Cortazar apud Néspolo, 2004)

No filme, o tempo borgeano instaura-se através dos flashbacks, visuais e sonoros (memórias de Aballay), que invadem a narrativa cronológica; dos ralentis, que expandem o tempo da ação; e das cenas em que som e imagem em descompasso causam um estranhamento temporal.

À semelhança dos contos gauchescos de Borges, o texto de Di Benedetto retoma o mito do gaucho, chegando a fazer referências diretas à tradição literária gauchesca como a alusão a Facundo: "Se nombra a Facundo, por uma acción reciente. ("Que no es que lo habían muerto, hace ya una pila de años?)" (Di Benedetto, 2010: 8). Além disso, para narrar as agruras da escolha de vida de Aballay, Di Bendetto revisita vários tópicos da literatura gauchesca: o temor aos militares e os problemas com a justiça, o refúgio no deserto, as rinhas de galo, a identificação do gaucho com seu cavalo, ações que transcorrem em ranchos e pulperias e a conotação pejorativa da palavra gaucho.

Aballay dialoga como a obra de Borges também através dos precursores que compartilham como, por exemplo, Martín Fierro. À semelhança de Fierro, que mata ao negro por crueldade, Aballay, no conto de Di Benedetto, comete um crime que, apesar de nada sabemos de suas razões, tudo indica ter sido um gesto de pura vileza intensificada pelo álcool: "Mató, y de un modo fiero. No se le perderá la mirada del gurí, que lo vio matar al padre, uno de los escasos recuerdos que le han quedado de aquella noche de alcohol" (Di Benedetto, 2010: 13). Também no filme, o ato sórdido e impiedoso de 
Aballay é um mero capricho em reação a uma provocação verbal. E, como em Martin Fierro, tanto no conto como no filme, Aballay será desafiado ao duelo pelo vingador de sua vítima, mas ao contrário do personagem de Hernández, ele não fugirá ao embate. E, nesse aspecto, novamente Aballay tangencia a obra de Borges, não apenas pela recorrência dos duelos a faca, mas por Borges realizar em "El fin" o duelo adiado por Hernández, que leva Fierro a finalmente encontrar o seu destino de gaucho, uma morte honrada. Para Beatriz Sarlo, com "El fin" Borges "adopta la única actitud que le parece posible frente a una tradición: traicionarla. La forma de la traición es contradecir otras interpretaciones del poema y volver a Hernández para concluir lo que allí había quedado abierto" (Sarlo, 1995).

Mas, assim como disse Borges a respeito de Hernández: hizo acaso lo único que un hombre puede hacer con una tradición: la modificó (Borges, 1975: 97), Di Benedetto e Spiner resgatam tradições para transformá-las. Em Aballay, Di Benedetto dá uma nova volta ao gênero gauchesco. Aballay é um gaucho que não se reconhece como tal, pois, como nos diz o narrador; ao ser convocado por um grito: Gaucho! ele não reconhece que aquele chamado era para si (Di Benedetto, 2011: 25). Além disso, sendo gaucho, é um gaucho culpado e penitente, muito diferente de Martín Fierro e Juan Moreira. E, diferentemente da percepção clássica de que é a imersão no ambiente selvagem, bem como a proximidade a seus habitantes, os índios, que tornam o gaucho brutal e quase bestial, em Aballay ocorre justamente o contrário: é na natureza que o protagonista consegue resgatar sua humanidade, é sua montaria que o torna menos bestial e nos índios ele encontra uma sabedoria atávica.

Outro diálogo entre Aballay e a obra de Borges é a releitura transcultural, criolla, do texto bíblico canônico. Aballay transcultura o texto bíblico que escuta, transpondo a história dos Estilitas para a cultura gauchesca. Aballay pode ser visto então como uma obra metanarrativa, que versa sobre o ato da leitura e, de maneira especial, sobre a leitura realizada na América Latina de textos fundadores da tradição eurocêntrica. Di Benedetto coloca em questão a leitura do texto bíblico pelo gaucho iletrado, uma leitura em segunda mão que ocorre através da pregação de um padre, confluindo assim com "El Evangelio según Marcos" (1970), de Jorge Luis Borges. Ambas narrativas sobre gauchos que, como disse Beatriz Sarlo a respeito do conto de Borges, "han olvidado un remoto pasado europeo, escuchan la historia evangélica y la traducen en términos de presente" (Sarlo, 1995: 23). Nos dois contos, o texto bíblico é lido para os gauchos por um estrangeiro, que serve de tradutor da linguagem escrita para a oral. E os gauchos, por sua vez, traduzem o que escutam a partir de suas experiências e de sua realidade, confirmando assim a máxima borgeana que iguala leitura e tradução.

$\mathrm{E}$ em ambos os casos é a interpretação, realizada através da leitura/tradução, a responsável pela ação dos gauchos: após escutar a história dos Estilitas, Aballay decide distanciar-se da terra, montando em seu cavalo 
para nunca mais apear; após escutarem a Paixão de Cristo, os gauchos borgeanos decidem crucificar o estrangeiro que lhes lera o Evangelho. E, além disso, assim como no conto de Borges, instaura-se um paralelo entre a figura de Aballay e a de Cristo: seja ao nomear-se como "um pobre", assim como se dizia Cristo nos contos populares, ou quando lhe oferecem pão e vinho, uma clara alusão à comunhão.

Aballay, tanto no conto quanto no filme, se transforma em um santo mitificado pela crença popular, que a ele atribui poderes "mágicos" de cura e de proteção. Uma figura envolta em mistério; tanto no contexto diegético, uma vez que os moradores da região desconhecem a origem de sua decisão de jamais desmontar do cavalo; quanto no contexto extradiegético, pois leitores e espectadores desconhecem o processo que o transformou em "gaucho mau", desconhecem a origem de sua violência.

Por outro lado, o homem que nunca apeia de seu cavalo recria a figura mitológica do centauro, ser híbrido: metade homem, metade cavalo. ${ }^{4} \mathrm{Em} \mathrm{El}$ Libro de los Seres Imaginarios, Borges associa as origens da criatura e do mito ao fato de que para aqueles que desconheciam a equitação o cavaleiro em seu cavalo era visto com um ser único: "Como los griegos de la época homérica desconocían la equitación, se conjetura que el rimer nómada que vieron les pareció todo uno con su caballo y se alega que los soldados e Pizarro o de Hernán Cortés también fueron Centauros para los indios” (Borges, 1978: 19).

No conto de Di Benedetto, a figura do centauro pode ser inferida da relação simbiótica estabelecida entre o ginete e seu cavalo, observada pelos índios que concluem não ser essa uma opção, mas sim um fadário, e o denominam: hombre-caballo. Ideia que é reforçada pelo narrador: "Forman uno Aballay y su cavalgadura; hace el segundo la outra bestia buena" (Di Benedetto, 2010: 20). Mas, ao contrário da figura mitológica em que o domínio da porção bestial significa sucumbir à lascívia, à embriaguez e à violência; em Aballay/centauro é justamente a porção animal que aplaca a sanha do gaucho. No filme de Spiner, o centauro se constrói através das imagens: nas cenas que apresentam a simbiose perfeita de Aballay com seu cavalo, que tudo faz sem desmontar, e no amuleto que representa o "Pobre" (alcunha dada pelo povo a Aballay), usado por Juliana e talhado por seu padrinho índio.

Por outro lado, para Borges, o ginete é um arquétipo universal: "Las historias de jinetes son muchas y podrían ser infinitas; aunque remotas en el tiempo y el espacio, son una sola, pues el protagonista - el jinete - es eterno" (Borges, 1989: 79). Desta forma, Aballay é Fierro, é Cruz, é Santos Vega, é Don Segundo Sombra e é todos os que virão.

4 A semelhança entre a relação de simbiose do gaucho com seu cavalo e a figura do centauro já é referida no filme El último centauro. La epopeya del gaucho Juan Moreira (1923), de Enrique Queirole. 


\section{Um duelo borgeano}

Outra importante confluência entre a obra de Borges e Aballay é o duelo como clímax da narrativa. O texto de Di Benedetto tem como mote um duelo, anterior ao tempo da narrativa, no qual Aballay mata um homem e guarda na memória o olhar acusador do filho deste, que presencia a cena. $\mathrm{O}$ filme de Spiner começa apresentando uma horda de gauchos errantes, liderados por Aballay, que vivem sob o jugo da violência. Ao assaltarem uma diligência, o líder do bando degola um homem sem saber que o filho da vítima assiste a tudo. Mas ao encontrar o menino que estava escondido, Aballay trava com ele um duelo de olhares, que se configura no jogo de câmera, campo/contracampo, em close-ups que apresentam alternadamente os olhos de Aballay e do menino. Este close-up nos olhos, imagem recorrente nos filmes de Western, principalmente, em episódios de duelo, já prenuncia o desenlace do antagonismo que se instaura nesse momento.

Aballay parece se reconhecer neste olhar de quem presenciou o horror. $\mathrm{O}$ áudio extradigético que invade a cena como uma memória auditiva de Aballay, com choros de crianças e mulheres, que parecem ser vítimas de um ataque tão violento como o que ele acaba de perpetrar, instaura uma elipse temporal rumo ao passado no qual o protagonista parece reviver a origem de seu histórico de violência. A história se repete, se duplica, ou, em um exercício borgeano, a narrativa se revela circular, levando Aballay a encontrar a esse outro Aballay. Esse enfrentamento entre o en e o outro, que se transforma no enfrentamento entre o eu e o mesmo, o confronto ao duplo, novamente nos remete ao universo de Borges: "Al fin y al cabo, al recordarse, no hay persona que no se encuentre consigo misma" (Borges, 2009: 15). E é através desse confronto que Aballay toma consciência de si mesmo.

O duelo entre Aballay e o filho já adulto de sua vítima será o desfecho de ambas as narrativas e nesse episódio a narrativa fílmica se mantém muito próxima à narrativa literária. Assim, o filme de Spiner, como um bom Western, culmina em uma cena de duelo. Mas, ao contrário dos clássicos do gênero e mais ao estilo do Western spaghetti, os personagens são dúbios e é complicado definir quem é o "mocinho" e quem é o bandido, ficando difícil ao espectador escolher por quem torcer.

Por outro lado, o duelo final entre Aballay e Julian remete aos duelos criollos a punhal recorrentes na literatura gauchesca e mitificados na contística gauchesca de Borges. O duelo com armas brancas, com um tanto de esgrima e de balé, representa a coragem e a honra do gaucho. E, tanto na literatura quando no cinema, é um vaticínio. Aballay, assim como Martín Fierro, é responsável por uma morte em duelo, mas, ao contrário deste, sente culpa por seu crime. No entanto, enquanto em La vuelta de Martín Fierro, o vingador enfrenta a Martín em um duelo de trova; Borges, em "El fin", promove um novo duelo entre eles, sete anos após a payada, no qual Martín morre e 
transmite ao Moreno o seu destino de assassino e de gaucho perseguido. O filme de Spiner, assim como o conto de Borges e diferente do conto de Di Benedetto, apresenta o duelo como uma repetição, um duplo do primeiro duelo de olhares travado entre Aballay e o menino/Julian, mas é também uma repetição do crime que Aballay queria evitar, pois acaba sem querer ferido seu oponente. Duplicação do eu no outro, o duelo transforma o vingador em assassino.

No conto de Di Benedetto, o filho vingador só aparece ao final da narrativa para cobrar sua dívida de sangue:

- Le he buscado.

- Mucho tiempo?

- Toda mi vida, desde que crecí (Di Benedetto: 39).

E para um duelo honrado, ele pede a Aballay que apeie, mas este se mantém impassível apesar de demonstrar consentir com o acerto de contas. Decidido a não ferir seu oponente e ao perceber que vai ser atacado, Aballay corta um pedaço de cana para defender-se como em um visteo. ${ }^{5} \mathrm{O}$ azar fará com que um golpe da faca de Julián transforme a cana de Aballay em uma lança pontiaguda que por inércia e destino acabou cravada em sua boca. Aproveitando-se do aturdimento de Aballay, ao desmontar para ajudá-lo, Julián consegue feri-lo mortalmente.

No filme de Spiner, o menino/vingador ganha um nome, Julian, uma história e um amor, Juliana. E é justamente ao tentar salvar sua amada, subjugada pelo Muerto, que ele acaba tendo os olhos gravemente feridos e, por obra da sorte, é entregue aos cuidados e à proteção do Pobre/Aballay. Vendado, ele não reconhece seu inimigo. E sem ver-lhe os olhos, Aballay tampouco o reconhece. Vagando sozinhos pela paisagem árida e expostos às intempéries, instaura-se entre eles uma relação de companheirismo e afeto como se fossem mestre e discípulo, pai e filho. Esse período de convivência, que não existe no conto, ressignifica o duelo final, dando novas cores ao drama, pois para vingar a morte do pai, Julian precisa matar o homem que o acolheu e o tratou. Assim, a cena do duelo recria o texto de Di Benedetto, mas possui um novo contexto que não havia na narrativa literária, intensificando a tensão do episódio que se torna muito mais dramático.

Em sua duplicidade monstro/santo, Aballay se assemelha ao Astérion de Borges, que, como ele, possui uma identidade híbrida (homem/touro), pois ambos se sentem acometidos pela maldição de ser quem são pela qual estão condenados a uma vida de errância, o primeiro pelas paragens argentinas, o segundo confinado em seu labirinto. Mas não será a imensidão da paisagem campeira o labirinto do gaucho? E, assim como no conto de Borges, em que Astérion ao ser atacado por Teseu "apenas se defendió" (Borges, 1989: 570)

5 Simulação do duelo criollo realizada para praticar a esgrima com as armas. 
também Aballay apenas se defende frente às investidas de Julian. Assim, a estocada que faz Aballay sucumbir iguala-se à libertação encontrada por Asterión na espada de Teseu, pois através da morte ambos encontram a redenção.

\section{O Western no cinema latino-americano contemporâneo}

Aballay insere-se em uma retomada que vem acontecendo nos cinemas contemporâneos latino-americanos e, em especial, no cinema argentino, ${ }^{6}$ do Western em seu entrecruzamento a uma identidade cultural alicerçada em um passado mítico regional e campesino. Essa revisão do gênero parece sinalar que em tempos cada vez mais economicamente globalizados e culturalmente mundializados, principalmente no contexto cinematográfico, há um movimento de reafirmação e resgate de identidades culturais regionais e/ou nacionais. Ou, quiçá, essa identidade "natural" rural nunca tenha existindo, sendo apenas uma construção resultante da reação transcultural ao colonialismo hollywoodiano, gerada do entrecruzamento entre a tradição local gauchesca e a tradição estrangeira do Western. Pois, como disse Borges, "la poesía gauchesca, que ha producido - me apresuro a repetirlo - obras admirables, es un género literario tan artificial como cualquier otro" (Borges, 1996: 158). E o mito do gaucho, nas versões narrativas modernas, como adverte Beatriz Sarlo, acaba por servir para realizar uma apologia de valores morais como: a ética da hombridade, a lealdade, a solidariedade e a coragem física (Sarlo, 2003), que talvez faltem à sociedade contemporânea.

Assim, é compreensível que esse passado mítico, heróico, fundador esteja tão presente e evidente no imaginário latino-americano e principalmente nos países com tradição campeira, surgindo como uma versão autóctone do Western hollywoodiano com cores intensificadas pelo Western Spaghetti. E cada um desses filmes, ao retomar e recriar essas memórias, colabora para a interrogação desse lugar imaginário e mítico onde nossas identidades foram forjadas.

\section{Referências}

BORGES, Jorge Luis (1978). El libro de los seres imaginarios. Barcelona: Emecé Editores.

${ }^{6}$ El Desierto Negro (2007), de Gaspar Scheuer, Argentina; Chicogrande (2010), de Felipe Cazals, México; Blackthorn (2011), de Mateo Gil, coprodução Bolívia, Espanha, EUA e França; Sal (2011), de Diego Rougier, coprodução Chile e Argentina; Los últimos cristeros (2011), de Matias Meyer, coprodução México e Holanda. E filmes como: El dedo (2011), de Sergio Teubal, Argentina; Vaquero (2011), de Juan Minujín, Argentina; Amateur (2011), de Nestor Frenkel, Argentina; Samurai (2012), de Gaspar Scheuer, coprodução Argetina e França, e Para los pobres piedras (2013), de Mathieu Orcel, também são atravessados por memórias transculturadas do Western. 
(1989). Obras completas. 1923-1949, vol. 1, Barcelona: Emecé. (1957). "El escritor argentino y la tradición” In: Discusión; Obras Completas. Buenos Aires: Emecé.

(1975). "Prólogo". En: José Hernández. Martín Fierro. Buenos Aires: Santiago Rueda Editor.

(s/d). Prólogo con un Prólogo de Prólogos [1975]. UFSC. Disponível em: http:/ / www.das.ufsc.br/ francisco/69511643-61712693-Jorge-Luis-

Borges-Prologos-Con-Un-Prologo-de-Prologos.pdf Acessado em: 17-062013.

DI BENEDETTO, Antonio (2010). Aballay (Incluye el guión cinematográfico de Fernando Spiner). Buenos Aires: Adriana Hidalgo editora.

GEADA, Eduardo (1978). Cinema e Transfiguração. Lisboa: Relógio D’Água.

GUTIÉRREZ, Eduardo (2012). Juan Moreira. Buenos Aires: Red Ediciones.

JOSET, Jacques (1987). A literatura bispano-americana. São Paulo: Martins Fortes Ltda.

LUDMER, Josefina (1988). El género gauchesco. Un tratado sobre la patria. Buenos Aires: Sudamericana.

LUGONES, Leopoldo (1991). El payador. Buenos Aires: Ayacucho.

MATTOS, A. C. Gomes de (2004). Publique-se a Lenda: A História do Western. Rio de Janeiro: Rocco.

NÉSPOLO, Jimena (2004). "Entre Lineas". Página/12. Buenos Aires, 12 de setembro 2004. Disponível em:

http://www.pagina12.com.ar/diario/suplementos/libros/10-1222-200409-12.html Acessado em: 14-08-2013.

PAZ, Octavio (1992). El laberinto de la soledad. México: Fondo de Cultura Econômica.

RAMA, Ángel (1984) La ciudad letrada. Hanover: Ediciones del Norte, 1984.

(1974). "Los procesos de transculturación en la narrativa latinoamericana", Revista de Literatura Hispanoamericana, N5: 9-38. http://revistas.luz.edu.ve/index.php/rlh/article/view/2901/2796

RANZANI, Oscar (2010). "Es un Western con todos sus tópicos", en Páginal 12, 22 de junho. Disponível em:

http:/ /www.pagina12.com.ar/diario/suplementos/espectaculos/5-

22068-2011-06-22.html Acessado em: 20-06-2012.

SARLO, Beatriz (1995). Borges, un escritor en las orillas. Buenos Aires, Ariel.

SARMIENTO, Domingo Faustino (1996). Facundo: Civilização é Barbárie. Petrópolis, RJ: Vozes. 